\title{
História(s) e Teoria da história: entrevista com Reinhart Koselleck*
}

\author{
History(ies) and Theory of history: Interview With Reinhart Koselleck
}

\section{Carsten Dutt}

cdutt@nd.edu

Assistant Professor

University of Notre Dame

O'Shaughnessy Hall, 318

46556 - Notre Dame - Indiana

Estados Unidos da América

Palavras-chave

História dos conceitos; Filosofia da história; Teoria da história.

Keywords

History of concepts; Philosophy of history; Theory of history.

Autor convidado

* Tradução feita a partir do original: KOSELLECK, Reinhart; DUTT, Carsten. Geschichte(n) und Historik. In: Erfahrene Geschichte. Zwei Gespräche, Universitätsverlag, Heidelberg, 2013. Carsten Dutten desempenha o papel do que indaga. Na tradução, distinguirei Historie e Historik como, respectivamente, historiografia (i.e., a história dos historiadores) e teoria da história. Tradução de Luiz Costa Lima, professor emérito PUC-Rio, revisão de Johannes Kretschmer. 
1. Carsten Dutt: Jacob Taubes, certa vez o chamou de "guerrilheiro" das histórias no plural contra a história, no singular (TAUBES 1973, p. 493). Esta característica se relaciona a um elemento polêmico, que se encontra em muitos de seus trabalhos, desde Crítica e Crise a seu confronto com a moderna filosofia da história. Contra o conhecimento especulativo do curso temporal e as determinações universais de meta com as quais se instala o paradigma histórico-filosófico da "história", no coletivo singular, o senhor lembra das múltiplas trilhas, da heterogeneidade e divergência dos acontecimentos tematizados pela historiografia, por outro lado, mas, sem articular o foco nas histórias na história, com uma enfática posição narrativista, que explicaria ser o relato a única forma legítima de apresentação da história. Minha primeira pergunta é como o senhor hoje retrospectivamente encara sua crítica à filosofia da história?

Reinhart Koselleck: Pois bem, a dificuldade oriunda da filosofia da história consiste em que os sistemas idealistas hipostasiaram todos os esboços da história geral em uma meta hipotética ou procuraram prová-la. Esta reivindicação de totalidade, traduzida em termos políticos, é totalitária, com a consequência conhecida, especialmente no marxismo, que representa um efeito desta filosofia idealista da história. Pode-se ao contrário introduzir teoricamente a pluralidade de histórias e, segundo penso, corretamente. Por certo, com a reserva de que a pluralidade das histórias particulares - que sempre podem ser aporéticas e mutuamente se excluir, e não permitem alguma interpretação abrangente, 312 mas, sim, contradições, que, justamente as multiplicam - que essa pluralidade a que aponta, a partir do século XX, toda a história e cuja conceitualidade histórico-filosoficamente revestida tenho eu por certo criticado. Deve-se abordar esse conjunto de pluralidades das histórias como um problema moderno, especialmente do século $X X$ e do século em curso. De fato, é um problema aberto - não resolúvel pelas teleologias da história, como tampouco pelas narratividades - em que medida essa generalidade e articulada, empiricamente efetivada pelas técnicas da comunicação, da informação, da circulação, terá efeitos na estrutura política da multiplicidade de histórias.

2. CD: Segundo uma formulação inesquecível, o senhor tem repetido de maneiras diversas que, depois do fracasso da filosofia da história (Geschichtsphilosophie), a tarefa central para a teoria da história (Historik) consiste em explicar "as condições das histórias" (Geschichten) possíveis (KOSELLECK 2000, p. 99). Se vejo corretamente, esta abordagem, apesar do empréstimo decisivo feito à linguagem da filosofia transcendental, orienta-se com determinação pela teoria do objeto (e não propriamente a partir da teoria do conhecimento, como antes com Droysen ou a partir da teoria da representação, como hoje, por exemplo, em Ricoeur). Para o senhor, trata-se de desenvolver categorias, que ajudem a entender por que as histórias, em geral ocorrem, e como podem transcorrer. $O$ senhor tem mantido este programa em diversos escritos, a começar, nos anos de 1960, com a elaboração das estruturas formais do tempo, cujo espectro deve registrar as formas possíveis de transcurso. A partir da década de 80, 
o projeto então se deslocou com nitidez crescente rumo ao reconhecimento de relações fundamentalmente antropológicas das histórias. Especialmente em confronto com a análise da existência (Daseinsanalyse) heideggeriana, mas também com o modelo teórico da hermenêutica filosófica de seu professor, Hans Georg Gadamer, o senhor tem projetado oposições elementares de uma antropologia, que, para isso, explica que a criatura conflitiva, o homem, sempre volta a se enredar nas histórias (Geschichten). Desejaria que o senhor mais uma vez falasse deste tema, antes de na discussão de alguns problemas e de questões de detalhe.

RK: O conceito da antropologia como conceito de base para as histórias possíveis é, na verdade, mais a descrição de um programa do que já seu resultado empírico. Pois mesmo as categorias antropológicas formais que desenvolvi sempre necessitam de confirmação empírica para que possam ser convertidas em uma teoria da história. Com essa prévia limitação à pesquisa concreta, quero por certo apontar para o fato de que algumas determinações estáveis e formais são inerentes à natureza humana, que se manifesta, de modos bastante diversos, nas histórias individuais. Isso vale desde as Histórias de Heródoto até às histórias modernas do terror, que, como, nos dias de hoje, devemos voltar a ver, podem ter repercussões globais. Que categorias formais são elas? São, fundamentalmente, três oposições, que posteriomente reencontrei em Goethe, sem que delas antes soubesse: antes - depois, interno - externo, sobre - sob. São categorias bastante formais, sem as quais, no entanto, nenhuma história (Geschichte) é pensável. Quando se leva isso a sério, destas categorias podem-se derivar formas de conflito - conflitos porque determinações de diferença temporal e social são necessariamente produzidas por essas refrações estruturais. Ou seja, quando tenho uma teoria do conflito, que sempre é produtiva, tenho em vista a mecha de problemas possíveis, os primeiros sintomas geradores de conflitos. E o mais importante parece-me ser que as histórias não terminam eo ipso harmonicamente, como sempre reiteraram os filósofos da história, i.e., que as histórias teriam estruturas diacrônicas diacronicamente capazes de cumprimento, senão que diacronicamente vemos que sempre se abrem novos conflitos, de nível alto ou profundo. A segunda determinação permanente ocorre naturalmente fora dos chamados pares opositivos, na determinação diferencial entre linguagem e história não verbal, que, na verdade, pode ser sempre requestionada pela reflexão hermenêutica fundamental da filosofia de Gadamer; segunda determinação que sempre pode revisada pois tudo que o homem pensa e faz é verbalmente condicionado. Mas a questão que não me parece possível é se esta determinação é suficiente para se derivar todas as histórias (Geschichten) e a história (Geschichte), in toto, como um evento verbal. Por isso a determinação diferencial entre linguagem e história permanece um diagnóstico que diferencia cada teoria da história (Historik) de todo tipo de hermenêutica.

3. CD: Em Wahrheit und Methode, Gadamer chama, de fato, a historiografia (Historie) de "uma espécie de filologia em geral". Isso me parece uma formulação 
bastante problemática, pois, de fato, ignora que a relação do historiador quanto às realidades do texto, que Ihe servem de material para suas pesquisas, é bem diversa da relação do filólogo quanto à poesia (assim como da do jurista quanto ao texto do direito em vigência ou do teólogo com a verdade revelada). Para o historiador, o texto transmitido pela tradição não é precisamente a instância final. Os textos serão indagados pelo historiador a propósito de algo que é por eles documentado, de que, possivelmente, são apenas o testemunho deformado.

RK: De fato, o fenômeno básico em todo o trabalho com a história (Geschichte) consiste em que os textos são, na verdade, necessários para serem compreendidos, para que sejam recontados ou ditos de novo ou reescritos. Sem textos, não posso realizar história alguma; mas eles não são a instância derradeira, pois texto algum já oferece aquilo a que visa a história. Fonte alguma, como se lhe define, basta para originar a história a que remete. Cada história exprime ora mais, ora menos do que pode dizer a fonte. Isso já é válido para as estruturas de evento das histórias (Geschichten), que, em eventos bem narrados, se aproximam, com frequência, dos eventos factuais, mas nunca são redutíveis a uma determinação deles. Isso ainda vale para decursos de longo prazo, que não se fundam em uma única fonte e cujas fontes precisam ser reconstruídas, para que longos transcursos possam ser inseridos, por exemplo, estatisticamente, por séries de fontes com um padrão de cunho temporal que tematiza a diacronia, que, enquanto tal, não se encontra em fonte alguma. Daí

314 que seja sempre, caso assim se queira, um procedimento transcendental que as condições de histórias (Geschichten) possíveis derivem dos textos, sem que fonte alguma possa explicar a história (Geschichte).

4. CD: Ainda sobre a relação da teoria da história (Historik) com a antropologia. Um empreendimento que visa a condições antropológicas e, neste sentido, metahistóricas, de histórias possíveis (ao homem), não deveria ter em conta apenas os potenciais de conflito, como as relações sobre - sob, dentro - fora, etc, potenciais que são fixados pela condition humaine, e, nesta medida, não podem ser estruturalmente suprimidos? Tal empreendimento não deveria ter em vista também a faculdade humana de solução de conflito e, neste contexto, tratar da adequação da razão como monopólio dos homens? Podemos não só nos matar e vencer uns aos outros como também nos unir, exercer a justiça e, até, como Hannah Arendt tão expressivamente lembrou, em sua antropologia política, perdoar. No senhor, estranhamente, estes aspectos passam a segundo plano. Há uma passagem nos Zeitchchiten em que é claramente dito: "Em si mesma, a história (Geschichte) é irracional. No melhor dos casos, racional é sua análise". Não se poderia objetar: tudo isso é insípido, ou seja, reflexo negativo do entusiasmo histórico-filosófico? Não é possível encontrar um lucro de racionalidade, não é possível analisar processos de aprendizagem na história, em suas condições e em seus componentes, e trazer à baila no sentido de um fortalecimento, historicamente refletido, destes processos? 
RK: Naturalmente, tem sentido descobrir a razão na história como postulado ou como programa político, pois seria absurdo afirmar que os homens, envoltos nas histórias (Geschichten) e capazes de eliminar uns aos outros, seriam a priori irracionais. O apelo à razão pertence por certo ao programa mínimo de cada política. A questão é apenas se, na história (Geschichte), a razão também aparece, se diferentes unidades de ação, com suas próprias projeções racionais, sem que possam se comunicar, engendram novos conflitos. Um conflito chega ao fim quando um novo conflito começa. Assim os próprios conflitos não se solucionam definitivamente, senão que propriamente apenas se dissolvem noutros conflitos estruturados. Essa é a experiência que até agora a história geral (gesammte Geschchite) oferece, a qual, naturalmente, se pode interpretar racionalmente, sem que daí se deduza que esta série de conflitos por si produza uma razão melhor. Pode-se, sem dúvida, esperar por isso, intentar-se tal meta, politicamente esperá-lo, mas não com uma antropologia da história que definisse essa transformação da razão como automática (Selbstläufer). O risco está em que, pela suposta razão da história, nos subtraíssemos da responsabilidade. Foi isso que tentei mostrar em minha tese de doutorado com a aporia do Iluminismo (KOSELLECK 1973). ${ }^{1}$

Vale, de resto, o análogo com outro monopólio humano: com a moral. Minha hipótese consiste em que a dimensão moral de todos os campos de ação sempre está presente nos planos político, econômico, também no religioso e no teológico, sem que a dimensão moral represente o modelo ou instância final dos processos decisórios. Ou seja, tanto quanto o imoral é produzido, por exemplo, na história política ou na militar ou mesmo na história do terror, tanto mais forte é o modo deficiente das implicações morais. Contudo este modo deficiente de ausência moral pode ser mostrado. Nesta medida, a apreciação negativa da falha moral é necessária para a falha do que sucede. Por isso, ainda que não se possa concluir que a história seja o tribunal do mundo e o que salda a falha moral, seja no além, seja mesmo nesta história, conforme esta interpretação otimista e, afinal, terrorista do mundo, segundo a qual tudo que sucede já é o cumprimento do direito e da moral - mesmo que esta posição não seja aceitável, permanece a instância negativa da falha moral e das causas das mesmas, sem as quais, por certo, não se pode julgar nenhuma ação política. Assim talvez seja extremo dizer que a moral significa o controle negativo do que de fato sucedeu. Mas o fato sucedido nunca é eo ipso moral.

5. CD: Não há dúvidas quanto ao potencial analítico-tipológico e exploratório até agora oferecidos pelos pares opositivos "fora - dentro, sobre - sob, antes - depois" das categorias de sua historiografia (Historik), enquanto esquemas multiplamente executáveis de relações de potencial histórico-geradoras, a possibilitarem comparações, assim como a tornarem visíveis diferenças entre histórias (Geschichten). Semper idem, sempre alter. Em que, contudo, as categorias contribuem para a reconstrução de histórias particulares e sequências

1 Tradução brasileira: KOSELLECK, 1999. A primeira edição alemã foi publicada em 1959, FreiburgMunique, Alber. 
de histórias particulares, para o conhecimento de sua formação, de seu transcurso e de suas consequências? Em cada caso, hão de se produzir esclarecimentos, de alcance maior e mais profundo, bem como muito específicos, não dedutíveis da trama de suas determinações opositivas elementares.

RK: Por certo, como tal, o conceito de reconstrução relaciona-se com o que se define por histórias, que possam ser demonstradas a partir delas mesmas. Deste modo, o conceito aludido não produz uma construção, mas, sim, apenas uma reconstrução; no fundo, portanto, apenas uma interpretação do que de fato sucedeu. Isso é possível quanto aos conjuntos de eventos, nos quais o homem em ação ou grupos humanos efetuam ações empiricamente imagináveis, passíveis de serem reconstruídas. Daí decorre, por exemplo, a simplicidade da história diplomática ou também da história política, cuja recontrução, neste sentido, é possível, pois os agentes, suas ações e omissões, e os motivos dos quais elas dependem, podem se tornar visíveis. Ao contrário, os verdadeiros conflitos que transcorrem por longo tempo e, assim, se estendem por gerações de agentes, que não têm qualquer fonte, como já disse, concernem menos a uma reconstrução do que a um esboço de história possível, cuja plausibilidade será construída pelas evidências na conexão de fontes, concebida pelo historiador. Na verdade, esta não é uma invenção da história, mas uma descoberta; e a descoberta relaciona-se a conexões que necessitam de uma antecipação teórica. Por exemplo, se se analisam os constantes conflitos geracionais ou se se observam as relações de 316 produção e as forças de produção, no sentido de Marx, por séculos, para que se veja quando se tornou possível um salto qualitativo, por exemplo, através da tecnização da produção. Há assim muita pesquisa de longo prazo, que não emerge de eventos isolados, mas que condiciona o evento particular.

Neste contexto, é particularmente importante uma indicação de meu posicionamento: o muito empregado conceito de duração, a longue durée de Braudel, tão usado entre nossos colegas, induz a um grande equívoco. Pois a duração não é nada estática. O estático se encontra em todas as partes da natureza, enquanto padrões não humanos, na história da natureza por milhões de anos ou por centenas de milhares, permanecem constantes ou mudam apenas muito lentamente, como, por exemplo, no período glacial. Mas os modos de ação, encarados a curto ou médio prazo, não são definíveis como duradouros, no sentido de serem estados constantes. Ou melhor, cada duração implica repetição, i.e., em cada evento particular estão contidos inúmeros modos de conduta, mentalidades, projetos subjetivos, regulamentações institucionais, etc, todas dependentes de que se repetem. Na repetição, há naturalmente uma ação e um evento, mas é um evento não legível por sua singularidade, senão em função do que se repete no evento e em sua singularidade. É muito difícil estabelecer percentualmente, mas, em termos grosseiros, diria que todos os eventos contêm mais do que $50 \%$ de todos os eventos contêm estruturas de repetição, que reviverão e se consumarão in actu. O conceito de duração é assim de todo modo também um modo de ação, que é sempre singular, mas inclui repetições na soma das singularidades, que, de sua parte, dificilmente são 
averiguadas a partir das fontes, pois estas se relacionam tipicamente com os eventos singulares. Isso exige uma antecipação teórica, que, pelo que sei, não foi até hoje pensada na prática, na empiria da pesquisa, por história (Historie) alguma, aliás, muito menos por mim.

No meu livro sobre a Prússia (KOSELLECK 1967), procurei investigar as estruturas de repetição do direito, atuantes por um século, para daí mostrar o que, ainda assim, mudava nas condições sociais do direito. Por essa razão se originavam conflitos, embora o direito permanecesse o mesmo. Os conflitos surgiam, pois as relações sociais, que incidem em questões de direito, se modificavam e tais conflitos eram, em consequência, explicáveis apenas pelas estruturas de repetição, que permanecem idênticas a si mesmas, fazendo com que, tendo em conta os casos de que tinham de tratar, se produzissem quase injustiças.

À primeira vista, parece que a singularidade oferece uma história mais efetiva, à medida que intervém no curso particular do dia a dia e que os agentes politicos investidos da capacidade decisória serão diariamente postos diante de novas alternativas, de que derivam discussões, conflitos e suas soluções. Mas nestas singularidades encaixa-se uma quantidade de padrões de repetição, que, falando cronologicamente, remontam a séculos ou meio século e configuram as condições de singularidade possível. Se cada uma delas fosse singular, criar-se-ia um oco; se tudo fosse novo, não se saberia de modo algum onde se poderia agir. E isso nos conduziria à pergunta sobre que de fato se repete para que se possibilite a unicidade? De quantas pressões de repetição ou estruturas de repetição se precisa - se for o caso de precisarmos - para podermos ser inovadores? Esta é a pergunta central, teoricamente central, que emerge de todas as situações políticas.

Pense por exemplo na história de unificação da Alemanha de Bismarck, muito tratada do ponto de vista ideológico-crítico. Do ponto de vista estrutural, tratava-se aqui de uma fundação constitucional de cunho monárquico, em defesa do povo alemão; assim a constituição foi então definida e nela estavam contidos os padrões federativos baseados na aliança entre os príncipes. Isso não é idêntico ao componente democrático que Bismarck introduziu pelo direito ao sufrágio universal, o que, com a fundação da Alemanha unificada, o fazia bastante moderno. Mas, mesmo em vista da federação de príncipes, restaurava um modelo de ação, que, na história alemã, remetia à metade de um milênio, mediada por experiências sempre novas: pelas dificuldades das federações, o império era tanto minado, como preservado. As duas grandes instituições judiciais do Sacro-Império Romano-Germânico (A Câmara do tribunal do império e o Conselho áulico), por um lado, e as intervenções constantes dos estados vizinhos, por outro, provocavam a preocupação com a manutenção de uma estrutura federativa interna sempre em perigo. Bismarck também utilizava um instrumental, que, presente na história alemã, não encontrava similar em qualquer outro país da Europa - pense na união aduaneira, dentro da federação. São estruturas de repetição que exprimem as condições de liberdade de ação possíveis, surpreendemente empregadas, de maneira poderosa, por Bismarck. Em 1848, a unificação fracassou, provavelmente pelo excesso de identificação 
nacional. Ninguém queria levar a cabo um modelo federal sob a pressão da hegemonia da Prússia e da Áustria, sem a qual nada acontecia. Mas Bismarck usou o conhecimento desta revolução; por assim dizer, ele implementou a solução mínima de uma hegemonia da Prússia sobre o plano federal, que então, no curso do reinado de Guilherme II, mudou muito rapidamente.

São intuições que se deve operacionalizar para introduzi-las, metodicamente, na ciência da história. Aí se produziu pouco, e eu também, penso, produzi muito pouco nesta área.

6. CD: A pesquisa da história torna visíveis as mudanças de estrutura de longo prazo e, por assim dizer, insidiosas; processos que ultrapassam muitas gerações; capacita talvez tornar evidente algo que não fora registrado pelos próprios contemporâneos e que não podia ser conscientemente experimentada. A este respeito, há uma experiência da história dependente da ciência: a aquisição do método de interpretação profissional da história. O senhor se ocupou em diversos trabalhos com a história (Geschichte) da história (Historie). O que o senhor achou é, no todo, evidentemente uma história do progresso: da acumulação de instrumentos que possibilitam novas fontes de experiência e contribuem para a produção do conhecimento, que, de sua parte, é então acumulado, dispõe-se na memória da ciência institucionalizada. Mas também chama a atenção para as perdas, particularmente no que concerne às possibilidades de representação da consciência investigadora.

RK: Por certo, o progresso científico mostra-se naturalmente no contexto de critérios racionais, que há na exegese das fontes, no aceso metódico e na preparação das fontes - a começar na arqueologia até às exegeses textuais e nas realizadas pelos especialistas mediáticos de agora. Dentro destas condições contextuais, há critérios que permitem controles racionais e assim impelem a um processo de conhecimento irreversível - não obstante as condições deste processo. Se, com Thomas Kuhn, se tematizam as revoluções nas ciências (KUHN 1962), pode-se apenas dizer que, apesar de todas as singularidades e criações geracionais e mudanças paradigmáticas, há demonstrações que permanecem cumulativamente legíveis. Seria ruim se assim não fosse. Pois, do contrário, nos exporíamos a nós mesmos como prova da mais absoluta tolice. Mas, por outro lado, há perdas a considerar, não compensadas e consistentes com estes progressos do conhecimento. Diria que são antes relações assimétricas. Há um cálculo de perdas que escapa do controle racional da ciência, que está em sua retaguarda, transversalmente estendido. O exemplo clássico é a invenção (no discurso historiográfico) da fala, por Tucídides, que continuou sendo imitada até o século XVIII. O próprio Ranke intercalou a fala em suas narrativas, que, no entanto, derivava diretamente das fontes. Assim, ao contrário de Tucídides, não produzia uma fala inventiva. A fala inventada por Tucídides, no entanto, tem a grande vantagem de poder afirmar, quase poeticamente, porém em menos páginas do que cada fala realmente observada, na situação política de confronto. Deste modo, Tucídides teoricamente é capaz de reservar à fala encargos reservados 
aos pensamentos já pensados e aos pensamentos falados, que de outro modo não se tornariam visíveis. Esta é uma realização estética que, neste sentido, leva vantagem sobre uma fala reconstruída ou redatada, por apresentar melhor as condições teóricas da fala possível do que teria sido possível sem as falas inventadas. Pode-se assim dizer que isso provoca uma perda, pois a imaginação é suplantada; que, com o recurso da fala inventada por Tucídides se ofereciam formulações teóricas superiores para a ciência da história.

7. CD: Talvez se pudesse dizer que este déficit é equilibrado na modernidade por uma espécie de divisão de tarefas entre a ciência da história, que renuncia a esta e outras estratégias ficcionais, e a prosa literária, que delas se apropria. Poder-se-ia considerá-lo como uma relação complementar. Muitos romances significativos - desde o Guerra e paz, de Tolstoi até Os dias do ano, de Uwe Johnson - são por certo apreciáveis como obras de escrita da história, mesmo se, naturalmente, enquanto tais não sejam obras que se submetem às limitações das técnicas de descrição, à "disciplina da verdade" da historiografia (Historie).

RK: Pode-se, por certo, dizer que são complementares. Mas esta não é uma situação de equilíbrio senão que, por assim dizer, de assimetrias mútuas, que então se tornam evidentes. Sem dúvida, o processamento literário de experiências historiográficas e históricas, é não só esteticamente mais fascinante de ler do que a maioria dos textos históricos como tem a grande vantagem de, por exemplo, reduzir simbolicamente a formação de conflito em situações que permitem ser ditas em poucas páginas, em vez de em metros da edição das fontes. Por isso, a história contada é muito mais próxima do ponto de vista do romancista, do epos do que a edição crítica das fontes. Cada história contada leva a um campo em que a imagem é necessária para produzir um mínimo de consistência, um mínimo de força simbólica expressiva ou um mínimo de sentido, sem os quais os relatos seriam impossíveis. Por exemplo, Die Verlobung in St. Domingo (O Noivado em Santo Domingo), de Heinrich von Kleist é uma estória de amor em cuja formulação simbólica de conflito está contida toda a Revolução Francesa. O mesmo vale para o Billy Bud, de Melville. Cerca de 100 páginas bastam para mostrar simbolicamente todos os conflitos da Revolução Francesa e o embate travado entre a França e a Inglaterra. Há, de fato, muitas realizações poéticas, que, também como historiador, eu valorizo em grau mais alto do que uma coleção de fontes estatiscamente manejável, a qual fornece outro modo de acesso. 0 aprofundamento, que é uma parte muito importante da solução humana de experiências não se deveria atribuir sem mais nem menos à pura ficção; deve-se antes admitir muitos poetas formularam experiências históricas de tal modo que a plausibilidade e o conhecimento real daí provêm. Penso também nos romances de Faulkner, diante do pano de fundo da guerra civil americana. O perspectivismo, a multiplicidade das camadas da experiência que reciprocamente se excluem são, por certo, um de seus grandes temas. Ou seja, as experiências em cada ocasião provocadas e fraturadas são combinadas, em seus romances, de um modo que se pode acompanhar como conflitos insolúveis nascem e se distendem. 
8 CD: Desde o Metahistory (WHITE 1973), de Hayden White, discute-se intensamente sobre a dimensão poética da historiografia liberada e não só das descrições de um gênero como o romance. Em conexão com as formas arquetípicas de modelagem narrativa do mundo, de Northrop Frye, White desenvolve uma poética da escrita da história, que também descobre as formas arquetípicas de modelagem narrativa do mundo - romance, comédia, tragédia e sátira - nas descrições de obras de histórias, estritamente ligadas a fontes. Como, em suma, o senhor avalia a discussão da narratividade e da poeticidade, ainda em curso, na teoria da ciência da história?

RK: Eu mesmo editei White, para torná-lo acessível ao público alemão (WHITE 1986). ${ }^{2}$ E o critico, apesar da amizade que mantenho com o autor. White desenvolveu um acesso justificado, que tematiza o status verbal da narrativa da história e a escrita da história. Nesta medida, lança a história na vizinhança de gêneros, que também são trabalhados na teoria da literatura (Literaturwissenschaft), na história da literatura ou na história da retórica. É um tanto controvertido tratar as categorias da retórica como conceitos de gênero, mas este é um problema secundário. A questão principal está em que White falha no que diz respeito à ciência da história. Esta constrói para si mesma em uma instância de controle da exegese de fontes, sobre cujas barreiras metódicas ela sempre deve saltar, para que se identifique como ciência. White não consegue ver que esta instância de controle da 320 exegese das fontes só depende do homem. Por isso sua análise é inspiradora, excitante, mas de curto alcance quanto à diferença entre escrita da história e ciência da história. Com suas categorias, White não pode alcançá-la. Essa é uma grande desvantagem. E a moda, que hoje volta a descobrir a narratividade, também é, no fundo, uma reação contra uma escrita da história sociologizante, extremamente analítica, e talvez mesmo contra a sociologia. Mas não quero tratar disso agora. A problemática, deste modo, falha porque os critérios científicos imanentes não podem ser metodicamente superados por complementação narrativa, por dissolução ou por superação. Devemos assim manter os critérios científicos imanentes, com os quais, naturalmente, não determinamos como o historiador depois escreve. Como se manifesta o modo de escrita do historiador é, em última análise, articulado à sua própria capacidade artística de se exprimir. Isso evidentemente o põe nas proximidades da literatura. Duvido, contudo, se daí deve-se inferir a consequência de que a narratividade possa ser uma base de identificação. Creio que os que se dedicam à escrita da história se superestimem como grupo quando supõem poder, por suas narrativas, cultivar ou estabelecer identidades políticas, o que, de certa maneira, é uma esperança idealista de muitos narrativistas.

9. CD: O senhor, portanto, não é partidário da tese desenvolvida por Hermann Lübbe - também certamente vista por ele com a reserva de ser uma concepção

\footnotetext{
2 Tradução de: WHITE, 1982.
} 
parcial - da função da história como de apresentação da identidade (LÜBBE 1979, p. 277-292).

RK: É por certo uma supervalorização que tem a ver com o fato de se afirmar que, no século XIX, a escrita da história ocupava um lugar que lhe concedia uma posição quase equivalente à da teologia; que depois, com a crescente diferenciação entre ciência política, sociologia, etc, ela perdeu status e, acima de tudo, a necessidade de manter-se na atualidade, status que só articialmente era reposto. De resto, justamente por isso minha crítica aponta para a escola francesa dos Annales, que, encarada sob esta perspectiva, representa uma escrita da história puramente autística. Por isso Braudel começa por definir a revolução francesa como o ponto terminal da longue durée, a fim de escapar das complexas dificuldades, que, desde então, se apossaram da história francesa. Ou seja, a longue durée foi, com respeito à identificação francesa, um postulado idealista. O mesmo vale para o fundador atual da identificação. Os lugares da memória, de Pierre Nora, (1984-1992) são apenas francesas e os conflitos que, nos lugares franceses da memória, estão implicados com a Alemanha, a Grã-Bretanha, a Itália ou a Espanha, não são considerados a partir de perspectivas contrárias. Mas a ciência da história tem o dever de procurar expor os conflitos em suas diversas maneiras e não de buscar a identidade. Aí está a incrível vantagem da ciência da história, como evidentemente também da escrita da história, se nela a ciência se manifestar, pois que ela precisa ser lida contra a trilha em que as verdades, que não se fundam por identidade, se confundem com o conhecimento.

10 CD: Alegações de relevância externas à ciência, por exemplo, conceitos de atualidade politicamente definidos, são equivocadas. Análises contemporâneas não são "mais importantes" do que a pesquisa puramente de tempos passados.

RK: Concederia que as análises contemporâneas têm sempre a oportunidade de despertar no leitor normal uma curiosidade maior do que, por exemplo, temas aparentemente muito distantes dele; mas isso não é válido do ponto de vista da teoria da ciência e tampouco deveria sê-lo do ponto de vista da ciência política. O senhor tem plena razão. Do ponto de vita da teoria da ciência, o argumento de que aproximar-se da contemporaneidade significaria alcançar alta atualidade e grande relevância é fraco. Ao contrário, a relevância e a atualidade consistem em que se mapeiam as zonas de conflito, situadas além, das áreas de conflito individuais e de articulações pessoais, as quais sempre reaparecem. Em consequência, posso aprender mais a partir de Tucídides do que, por exemplo, de uma biografia qualquer de Helmut Kohl. As estranhas histórias passadas podem ser muito mais relevantes para o conhecimento do que a visualização instrumentalizada da história. Justamente agora, quando as oposições religiosas a crescer em escala mundial, é de se perguntar se o conhecimento das histórias de Maomé ou das suras não é mais importante para a política presente do que saber do curso diário das ações terroristas. 
De fato, a distância é talvez aí mais atual do que a proximidade. Uma vez que se compreenda isso, pode-se deixar de engolir a simples alternativa "atual" ou "antiguidade". Na história, tudo propriamente se relaciona entre si e qual perspectiva deve ser produzida para produzir conhecimento é por certo uma arte que devia caracterizar o historiador.

A vantagem da ciência da história de todo modo consiste em que ela, de fato, dispõe, como Goethe sabia, de um par de milhares de anos. Por isso ela habilita a encarar a atualidade pré-definida como um curso estreito, e compreender, em determinadas circunstâncias, como politicamente arriscado agir a partir da situação atual, Atualizações preparadas depressa fenecem. Também as identidades estabelecidas constantemente são de vida curta e sem fôlego. Tão curta como o que se compreendia, no século XIX, por "um povo alemão", então invocado como duradouro; tão curta como hoje é a "comunidade europeia", que aparece como identitariamente fundada. É natural que se pode agir politicamente nesta direção; pode-se também produzir argumentos históricos, mas a solução não é encontrada quando se funciona ou instrumentaliza a história. A história escapa de toda institucionalização. Ela sempre se vinga como um poder que se contém mais em si do que podem ditar as propostas de identificação.

11. CD: Em um ensaio que se tornou famoso, que antes apareceu no livro em homenagem a Karl Löwith, o senhor investigou a perda moderna de valor do 322 tópos historia magistra vitae, sua "dissolução no horizonte da movimentada história dos tempos modernos" (KOSELLECK 1967, p. 196-219). 3 O senhor concorda que eu ache que o ponto principal ou um dos pontos principais de sua "guerrilha" por uma historiografia (Historik) tematizadora de estruturas de repetição naturais, antropologicamente estabelecidas e historicamente contingentes, como condições de histórias possíveis, consiste na reabilitação daquele tópos? Quando estruturas de repetição se deixam identificar, então também podem ser desenvolvidos prognósticos que, talvez, não permitam derivar acontecimentos separados, mas que permitem dizer o que pode ser 0 caso e qual, provavelmente, será ele.

RK: O senhor está certo, o topos historia magistra vitae deixou de ser evidente, depois da Revolução Francesa, no século XIX, porque toda a história foi progressivamente compreendida como única. É este o axioma do chamado historismo. Cada época relaciona-se diretamente com Deus e, assim, é sempre singular. Esta singularidade evita que eu aprenda com um caso que aconteceu no passado, por ser ele singular. Na realidade, esta teoria da singularidade do historismo é um produto da acelerada sociedade industrial e revolucionária, que eliminou o estado estamental e precipitou o estado de igualdade democrática, analisado por Tocqueville. No entanto, quanto mais a singularidade se adiciona ao horizonte da industrialização moderna, tanto mais

${ }^{3}$ Republicado em KOSELLECK, 1989, p. 18-86. 
se enfatiza que as condições possibilitadoras daquela singularidade se repetem com força. Nesta medida, a ideia da historia magistra vitae volta em um plano teoricamente diferente. Não podemos pressupor singularidades, não sabemos o que o presidente Bush fará no futuro. Mas conhecemos os parâmetros dentro dos quais os americanos efetuarão agora, por exemplo, sua luta contra o terrorismo. As categorias e os diagnósticos com que os americanos operam naturalmente contêm elementos de repetição de sua visão política global de mundo, que, por certo, tem o aspecto prototípico de liberdade democrática, com o custo subsequente de repercutir noutras zonas do globo de maneira menos prototípica.

O que distingue a modernidade, convertida em conceito, é uma aceleração que não esteve presente nos objetivos naturais da humanidade. Desta maneira, a partir do século XVIII, a história se distingue fundamentalmente de toda a história passada, pois as próprias metas estruturais mudam mais rapidamente do que era antes possível. Isso começa com a força do motor a vapor e então passa para os aceleradores químicos, eletrônicos e atômicos, que modificaram por completo a rede geral de tráfego, as comunicações, de tal modo que podemos percorrer todo o globo em 24 horas, não de modo utópico senão factual, da mesma forma, as ocorrências em cada ponto do globo estão, ao mesmo tempo, presentes em todos os receptores de notícias. Ou seja, torna-se evidente uma lei, uma regularidade que, de resto, Henry Adams já formulava em 1904: "A lei da aceleração" (ADAMS 1918, p. 489499). Daí decorre que os aceleradores técnicos mudaram toda a estrutura da sociedade, os poderes econômicos e também a estrutura política de decisão. Já não podemos aguardar decisões passivamente; devemos antevê-las, para que que mantenhamos a cacapcidade de ação. Deve-se agora agir com mais rapidez, e, igualmente, com base nas possibilidades de repetição, prever a longo prazo, para que, atualmente se possa agir. Os acontecimentos e as notícias sobre eles convergem cada vez mais. Voltamos a vivê-lo agora com o ataque do terror em Nova York. O acontecimento foi temporalmente idêntico às imagens que vimos. Não há mais diferença entre o acontecimento, a exposição e a interpretação política, senão que estas últimas hão de ser teoricamente antevistas, para que possam influir nos acontecimentos. Nesta medida, toda a estrutura de ação foi modificada pela aceleração da rede de notícias e de circulação, o que também vale no campo militar. Mas antecipar significa prever, o que implica um mínimo de estruturas de repetição. Se isso falha, nada se deixa antecipar. Ou seja: o que agora deve ser antecipado é a preparação de repetições possíveis, para que, em suma, se ganhe alguma ascendência sobre o que sucede.

Nesta medida, historia magistra vitae sim, mas não no sentido de repetição de acontecimentos solitários senão de um prognóstico que meça o espaço possível de acontecimentos. 


\section{Referências bibliográficas}

ADAMS, Henry. A law of acceleration. In: The Education of Henry

Adams: an autobiography. Boston e New York: Houghton Mifflin, 1918, p. 489-499.

KOSELLECK, Reinhart. Crítica e crise: uma contribuicão à patogênese do mundo burguês, tradução de Luciana Villas-Boas. Rio de Janeiro: EDUERJ/ Contraponto, 1999.

- Historia Magistra Vitae. Über die Auflösung des Topos im Horizont neuzeitlich bewegter Geschichte. In : BRAUN, Hermann; RIEDEL, Mardred (orgs. ). Natur und Geschichte. Karl Löwith zum 70. Geburstag. Stuttgart, 1967, p. 196-219.

. Historik und Hermeneutik. In:

Zeichichten: Studien zur Historik. Frankfurt am Main, 2000, p. 97-118.

. Kritik und Krise: Eine Studie zur Pathogenese der bürgerlichen Welt. Frankfurt am Main, Suhrkamp, 1973.

- Preußen zwischen Reform und Revolution: Algggemeines Landrecht, Verwaltung und soziale Bewegung zwischen 1791 und 1848. Stuttgart, 1967.

. Vergangene Zukunft: Zur Semantik geschichtlicher Zeiten. Franfurt am Main, 1989.

. ; DUTT, Carsten. Geschichte(n) und Historik. In: Erfahrene Geschichte. Zwei Gespräche, Universitätsverlag, Heidelberg, 2013.

KUHN, Thomas S. The Structure of scientific revolutions. Chicago: The University of Chicago Press, 1962.

LÜBBE, Hermann. Zur Identitätspräsentationsfunktion der Historie. In: MARQUARD, Odo; STIERLE Karlheinz (orgs.). Identität. (= Poetik und Hermeneutik VIII). Munique, 1979, p. 277-292.

NORA, Pierre (org.). Les Lieux de mémoire. 7 vols. Paris, 1984-1992.

TAUBES, Jacob. Geschichtsphilosophie und Historik. Bemerkungen zu Kosellecks Programm einer neuen Historik. In: KOSELLECK, Reinhart; STEMPEL, Wolf-Dieter (orgs.). Geschichte - Ereignis und Erzählung. Munique, 1973, p. 490-499.

WHITE, Hayden. Auch Klio dichtet oder die Fiktion des Faktischen. (= Sprache und Geschichte, vol. 10). Stuttgart, 1986.

Metahistory: The historical imagination in nineteenth-century Europe.

Baltimore-Londres: The Johns Hopkins University Press, 1973.

Tropics of discourse: essays in cultural criticism, Baltimore e Londres. The Johns Hopkins University Press: 1982. 